\title{
Health-related quality of life and neurodevelopmental outcomes among children with intestinal failure
}

\section{Hukkinen, Maria}

2018-08

Hukkinen , M , Merras-Salmio , L \& Pakarinen , M P 2018 , ' Health-related quality of life and neurodevelopmental outcomes among children with intestinal failure ', Seminars in pediatric surgery. , vol. 27 , no. 4 , pp. 273-279 . https://doi.org/10.1053/j.sempedsurg.2018.07.004

http://hdl.handle.net/10138/306638

https://doi.org/10.1053/j.sempedsurg.2018.07.004

publishedVersion

Downloaded from Helda, University of Helsinki institutional repository.

This is an electronic reprint of the original article.

This reprint may differ from the original in pagination and typographic detail.

Please cite the original version. 


\title{
Health-related quality of life and neurodevelopmental outcomes among children with intestinal failure
}

\author{
Maria Hukkinen ${ }^{\mathrm{a}, \mathrm{b}}$, Laura Merras-Salmio ${ }^{\mathrm{a}, \mathrm{c}}$, Mikko P Pakarinen ${ }^{\mathrm{a}, \mathrm{b}, *, 1}$ \\ a Pediatric Liver and Gut Research Group, Children's Hospital, Helsinki University Hospital, P.O. Box 281, 00029 HUS Helsinki, Finland \\ ${ }^{\mathrm{b}}$ Section of Pediatric Surgery, Children's Hospital, Helsinki University Hospital, Finland \\ 'Section of Pediatric Gastroenterology, Children's Hospital, Helsinki University Hospital, Finland
}

\section{A R T I C L E I N F O}

\section{Keywords:}

Cognitive functioning

Psychomotor functioning

Short bowel syndrome

\begin{abstract}
A B S T R A C T
Treatment results of pediatric intestinal failure have improved markedly during the last decades. With improved survival the attention is turning to other essential outcomes including quality of life and neurodevelopment. So far, relatively few studies with limited number of patients and variable methodology have addressed these issues. Based on these studies using generic health related quality of life tools, children with intestinal failure demonstrate decreased physical health, while PN-dependence is also associated with compromised emotional functioning. Impairments of social functioning are frequently observed among older children and parents. Few recent studies on neurodevelopment imply significant impairments in motor and mental skills among children with intestinal failure despite small sample sizes and limited follow-up times. Development of a disease-specific survey designed for the pediatric intestinal failure population could better reveal the health issues with greatest impact on quality of life. Robust studies with appropriate methodology on neurodevelopment in pediatric intestinal failure with extended follow-up times are urgently needed. Quality of life and neurodevelopment requires greater attention from medical professionals managing children with intestinal failure.
\end{abstract}

(C) 2018 Elsevier Inc. All rights reserved.
Health-related quality of life (HRQOL) is an outcome increasingly used to assess the impact of chronic diseases on a child's well being. ${ }^{1,2}$ Compared to the traditional health outcomes, morbidity and mortality, HRQOL is a particularly meaningful outcome in the pediatric population, as it comprehensively measures the diverse factors influencing the child's functioning and well being. ${ }^{2}$ HRQOL is a multidimensional concept consisting of physical and psychosocial (including emotional, cognitive, and social) health dimensions, ${ }^{1}$ and is preferably based on patient self-assessment although parent proxy reports serve as a helpful adjunct particularly among very young or severely ill children. ${ }^{3}$ Another very important, closely related, and more objective pediatric health outcome is neurodevelopmental function, which carries significant long-term consequences and is particularly susceptible during the critical time of brain development in the neonatal period. ${ }^{4}$ Reliable assessment of neurodevelopmental skills involves the use of appropriate standardized age-specific tests, which evaluate a

\footnotetext{
* Corresponding author at: Pediatric Liver and Gut Research Group, Helsinki University Hospital, Children's Hospital, P.O. Box 281, 00029 HUS Helsinki, Finland.

1 Mikko P Pakarinen was supported by research grants from the Sigrid Jusélius Foundation, the Finnish Pediatric Research Foundation, and the Helsinki University Central Hospital Grant.

E-mail address: mikko.pakarinen@hus.fi (M.P. Pakarinen).
}

child's cognitive abilities and psychomotor function in relation to a reference population. ${ }^{4,5}$

Intestinal failure (IF) in children involves conditions where the bowel absorptive capacity is insufficient to maintain adequate nutrition and growth, warranting long-term parenteral nutrition (PN) instead. $^{6-8}$ IF is frequently defined as PN duration for over three consecutive months or small bowel resection $>50 \%$ of age-adjusted reference value. ${ }^{9}$ The most common reason for pediatric IF is short bowel syndrome (SBS) due to extensive bowel resection in the neonatal period for conditions such as necrotizing enterocolitis (NEC), midgut volvulus, gastroschisis, or small bowel atresia. ${ }^{7}$ In the current era of multidisciplinary treatment programs, SBS survival rates exceed $90 \%$ and the majority of patients are eventually able to wean off PN. ${ }^{9-13}$ Compared to SBS, primary intestinal motility disorders and mucosal enteropathies are less common reasons leading to IF but are associated with a lower likelihood of achieving enteral autonomy and possibly a higher risk for complications of prolonged PN. ${ }^{10,14}$

Thanks to advances in neonatal intensive care and improved safety of home PN due to increased understanding of the management and prevention of intestinal failure-associated liver disease (IFALD) and bloodstream infections, $6,7,9-11,13$ survival and IFrelated complications are no longer the only outcomes of interest among IF children. In adults with IF the HRQOL is influenced by 
abdominal pain, loose stools, eating problems, frequent hospital visits, and tiredness, ${ }^{15-18}$ as well as financial distress, anxiety, and depression, which also affect other family members. ${ }^{19,20}$ Further, home PN administration is complex and time-consuming, and the presence of central lines and stomas affect body image, complicate clothing, and disrupt leisure activities. ${ }^{15,17,18}$ The HRQOL in children and adolescents with IF has been examined less systematically. In addition to above-mentioned factors, their HRQOL may be influenced by fractures due to decreased bone mineral density, ${ }^{21,22}$ nephrolithiasis and impaired renal function, ${ }^{23}$ as well as anemia, infections, and poor growth caused by mineral and vitamin deficiencies. ${ }^{24}$ Such disease-specific and PN-related problems are taken into account in the recently developed IF-specific HRQOL instruments targeted for adults, ${ }^{17,18}$ whereas currently available outcomes among IF children are based on generic pediatric HRQOL questionnaires not necessarily addressing the known risk factors for decreased HRQOL in IF patients. ${ }^{25-28}$

Prematurity, baseline diagnosis, comorbidities, prolonged periods of critical illness requiring treatment in intensive care units, as well as factors related with surgery and PN administration practices may all negatively affect the neurodevelopment in children with IF. $^{29-31,31-33}$ NEC is an independent predictor of poor neurodevelopmental function, ${ }^{31,33,34}$ whereas patients with uncomplicated gastroschisis or small bowel atresia tend to show long-term outcomes comparable to healthy children. ${ }^{35-37}$ Multiple procedures under general anesthesia as well as long hospital stays during the early infancy may have a negative influence on both cognitive and psychomotor development. $5,29,30,38$ Moreover, PNrelated complications, such as IFALD, bloodstream infections, and potential nutritional deficiencies may interfere normal neurodevelopment. $^{32}$ The amount of lipids in PN solutions may be restricted to reduce the risk of IFALD, ${ }^{6}$ and whether this strategy predisposes to essential fatty acid deficiency and thereby jeopardizes child's neurodevelopment has also been a concern. 39,40

In this review, we summarize and discuss the previously published outcomes on HRQOL and neurodevelopmental outcomes among pediatric IF patients, evaluate the quality of available data, and outline challenges for future research.

\section{Measurement of HRQOL and neurodevelopmental outcomes}

Unlike for adult SBS and home PN patients as well as for pediatric asthma, diabetes, and gastrointestinal symptoms, ${ }^{17,18,25,41,42}$ no disease-specific HRQOL questionnaire for pediatric IF exists. The Pediatric Quality of Life Inventory (PedsQL) is a widely used and validated means to measure general HRQL among children, and its use enables comparison of the disease burden between different chronic conditions as well as to a pediatric normal population. $^{25,43}$ PedsQL Infant and Generic Core Scales are targeted for children aged 1-24 months and 2-18 years, respectively, and cover all dimensions recommended for a thorough HRQOL evaluation, including parent proxy-report formats for each age group. ${ }^{3,43}$ Validated multidimensional questionnaires for infants, children, and adolescents exist in non-English languages as well. ${ }^{44}$ In addition, questionnaires targeted at caregivers either covering all HRQOL subscales ${ }^{45}$ or assessing its specific dimensions, such as children's behavioral problems or the availability of social network have been applied for evaluating pediatric HRQOL. ${ }^{46,47}$

Neurodevelopment among infants and toddlers can be assessed with detailed standardized age-specific tests, such as mental and psychomotor index subscales of Bayley Scales of Infant Development or the Mullen scale. ${ }^{48,49}$ However, neurodevelopmental tests performed in the early infancy may not be predictive of the long-term cognitive outcomes among preterm infants. ${ }^{50,51}$ In older children, Griffiths Development Scales evaluating cognitive, socialemotional, and motor skills are suitable up to six years of age, ${ }^{52}$ while Wechsler intelligence tests are widely used among schoolaged children. ${ }^{53}$ In addition, some studies have defined neurodevelopmental impairment based on abnormal vision, hearing, or brain imaging findings. ${ }^{4,5}$ Parent rating instruments on child's neurodevelopment show moderate to high correlations with objective neurodevelopmental scores, ${ }^{54}$ and their use may facilitate evaluation of larger patient groups since detailed neurodevelopmental testing is both time-consuming and expensive.

\section{Summary of available studies among children with intestinal failure}

An electronic Medline search was made with different combinations of the keywords "children", "cognitive outcomes", "intestinal failure", "intravenous fat", "neurodevelopmental outcomes", "neurodevelopment", "parenteral nutrition", "quality of life", and "short bowel syndrome".

Eight cross-sectional studies evaluating the HRQOL of IF children were identified. Sample sizes varied between 7-72 patients and six studies were mainly performed among SBS children while patients with intestinal motility disorders comprised the majority in two reports (Table 1). In addition, two studies had included children with IF due to small bowel enteropathies or secretory diarrhea. ${ }^{28,55}$ One report was based on individual interviews, ${ }^{28}$ while others on mailed questionnaires (Table 1 ). Gestational age was reported in only one work, where preterm children comprised $50 \%$ and NEC patients $31 \%$ of the sample. ${ }^{27}$ In other studies among SBS patients, NEC had occurred in $6 \%, 2620 \%,{ }^{56}$ or $44 \% .{ }^{25}$ The results were compared to healthy children's scores in all but one study. ${ }^{28}$ Both patient-self report and parent proxy reports were recorded in three articles, ${ }^{25-27}$ while two studies had solely collected caregivers' answers. ${ }^{55,57}$ Overall, impaired physical functioning was reported in all studies while other HRQOL dimensions showed more variability in comparison to healthy controls (Table 1). Notably, all studies assessing mainly or exclusively PN-dependent children found impairments in emotional and social functioning (Table 1). Etiology of IF, baseline diagnosis, patient age, or other characteristics were unrelated with HRQOL outcomes in studies analyzing such associations. ${ }^{25,27,56}$

Four cross-sectional studies and one prospective follow-up assessing the neurodevelopmental outcomes among pediatric IF patients were identified; each based on relatively small samples sized from 8 to 33 patients (Table 2). Three most recent articles were almost exclusively confined to SBS patients with reported prematurity rates varying between $63 \%$ and $82 \%$ but NEC patients comprising the minority of participants. ${ }^{5,38,58}$ In addition to SBS, two earlier studies not reporting patients' gestational age had also included patients with primary intestinal motility disorders or mucosal enteropathies. ${ }^{59,60}$ A control group was used in only one work, ${ }^{58}$ while others interpreted the neurodevelopmental scores in relation to available reference data (Table 2). All studies including PN-dependent patients found impaired psychomotor scores among IF patients. The cognitive outcomes showed more variability: older children in the earlier studies were reported to have normal cognitive function, ${ }^{58-60}$ while younger children in the more recent studies showed decreased mental scores and language skills. ${ }^{5,38}$ Studies assessing the effects of specific patient-related factors on neurodevelopment identified the known risk factors, such as prematurity, NEC diagnosis, and prolonged hospital stay as predictors for cognitive impairment. ${ }^{5,38,59}$

Two prospective and one cross-sectional study evaluating the neurodevelopmental outcomes related to reduced administration of parenteral fish oil or soy oil were identified. ${ }^{54,61,62}$ These studies are outlined in Table 3. Each work was performed among patients with mean PN duration less than three months, and accordingly, not all participants fulfilled the generally applied 
Table 1

A summary of the published results on health-related quality of life among children with intestinal failure.

\begin{tabular}{|c|c|c|c|c|c|c|c|c|c|c|c|c|}
\hline First author, year & $\mathrm{n}$ & Main etiology (\%) & Questionnaire & Mean age & On PN, n (\%) & $\begin{array}{l}\text { Mean PN } \\
\text { duration }\end{array}$ & Self-report & Reference group & $\begin{array}{l}\text { Physical } \\
\text { health }\end{array}$ & $\begin{array}{l}\text { Emotional } \\
\text { functioning }\end{array}$ & $\begin{array}{l}\text { Social } \\
\text { functioning }\end{array}$ & $\begin{array}{l}\text { School } \\
\text { functioning }\end{array}$ \\
\hline Pederiva $(2018)^{54}$ & 30 & SBS (100) & $\begin{array}{l}\text { PedsQL } 4.0 \text { and PedsQL } \\
\text { parental questionnaires }\end{array}$ & 3.0 and $12 \mathrm{y}$ & $\begin{array}{l}6 \text { or } 7 \\
(20-23)\end{array}$ & $\mathrm{N} / \mathrm{A}$ & Yes & $\begin{array}{l}\text { Reference data; children } \\
\text { with chronic diseases }\end{array}$ & $\downarrow$ & $\leftrightarrow$ & $\downarrow$ & $\downarrow$ \\
\hline Mutanen $(2015)^{26}$ & 36 & SBS (64) & PedsQL 4.0 & $9.0 \mathrm{y}$ & $8(22)$ & $10 \mathrm{~m}$ & Yes* & Healthy controls & $\downarrow$ & $\leftrightarrow$ & $\leftrightarrow$ & $\leftrightarrow$ \\
\hline Sanchez $(2013)^{24}$ & 23 & SBS (96) & PedsQL 4.0 & $2.4 \mathrm{y}$ & $16(70)$ & $28 \mathrm{~m}$ & Yes* & Reference data & $\downarrow$ & $\leftrightarrow$ & $\downarrow$ & $\downarrow$ \\
\hline Olieman $(2012)^{25}$ & 31 & SBS (97) & PedsQL 4.0 & $11 \mathrm{y}$ & $0(0)$ & $3.4 \mathrm{~m}$ & Yes* & Healthy controls & $\downarrow$ & $\leftrightarrow$ & $\downarrow$ & $\downarrow$ \\
\hline Emedo $(2010)^{27}$ & 7 & SBS (50) & Interview & $13 \mathrm{y}$ & $13(100)$ & $\mathrm{N} / \mathrm{A}$ & Yes & - & $\downarrow$ & $\downarrow$ & $\downarrow$ & $\downarrow$ \\
\hline Gottrand $(2005)^{61}$ & 72 & $\mathrm{~N} / \mathrm{A}$ & Qualin / Auquei / OK.ado & $4.0 \mathrm{y}$ & $72(100)$ & $24 \mathrm{~m}$ & Yes & Reference data & $\downarrow$ & $\downarrow$ & $\begin{array}{c}\text { Adolescents } \downarrow \\
\quad \text { Children } \leftrightarrow\end{array}$ & $\begin{array}{c}\text { Adolescents } \uparrow \\
\text { Children } \leftrightarrow\end{array}$ \\
\hline Engström $(2003)^{53}$ & 20 & Dysmotility (50) & CBCL, ISSI & $7.0 \mathrm{y}$ & $20(100)$ & $57 \mathrm{~m}$ & No & Reference data & $\mathrm{N} / \mathrm{A}$ & $\downarrow$ & $\downarrow$ & $\downarrow$ \\
\hline Schwankovsky & 45 & Dysmotillity (100) & $\mathrm{CHQ}$ & $9.0 \mathrm{y}$ & $17(38)$ & $\mathrm{N} / \mathrm{A}$ & No & Reference data & $\downarrow$ & $\leftrightarrow$ & $\downarrow$ & $\downarrow$ \\
\hline
\end{tabular}

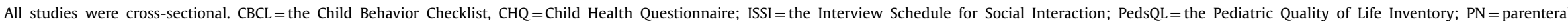
nutrition; SBS $=$ short bowel syndrome. $\downarrow$ impaired; $\leftrightarrow$ no difference; $\uparrow$ improved compared to reference group. *both patient self-report and parent proxy reports included.

Table 2

A summary of the published results on neurodevelopmental outcomes among children with intestinal failure.

\begin{tabular}{|c|c|c|c|c|c|c|c|c|c|c|c|}
\hline First author, year & $\mathrm{n}$ & Study design & Main etiology (\%) & NEC, n (\%) & $\begin{array}{l}\text { Mean age at } \\
\text { assessment }\end{array}$ & $\begin{array}{l}\text { On PN, n } \\
(\%)\end{array}$ & $\begin{array}{l}\text { Mean PN } \\
\text { duration }\end{array}$ & $\begin{array}{l}\text { Reference } \\
\text { group }\end{array}$ & Scales & Cognitive function ${ }^{*}$ & Psychomotor function* \\
\hline Chesley $(2016)^{37}$ & 15 & Cross-sectional & SBS (93) & $2(13)$ & $1.5 \mathrm{y}$ & $13(87)$ & $17 \mathrm{~m}$ & Reference data & $\begin{array}{l}\text { BSD-II; Differential Ability } \\
\text { Scales/Wechsler; hearing and } \\
\text { vision }\end{array}$ & Mental scores $\downarrow$ & Psychomotor scores $\downarrow$ \\
\hline So $(2016)^{5}$ & 33 & Prospective & SBS (94) & $12(36)$ & $\begin{array}{l}4,8 \text {, and } 12-15 \\
\mathrm{~m}\end{array}$ & $12(36)$ & $7.8 \mathrm{~m}$ & Reference data & $\begin{array}{l}\text { Head MRI; hearing and vision; } \\
\text { motor skills; the Mullen }\end{array}$ & $\begin{array}{l}\text { Receptive language } \downarrow \\
\text { Expressive language } \leftrightarrow \\
\text { Visual perception } \leftrightarrow\end{array}$ & $\begin{array}{l}\text { Gross motor skills } \downarrow \\
\text { Fine motor skills } \leftrightarrow\end{array}$ \\
\hline Beers $(2000)^{56}$ & 8 & Cross-sectional & SBS (100) & $2(25)$ & $9.8 \mathrm{y}$ & $3(38)$ & $39 \mathrm{~m}$ & CF patients & $\begin{array}{l}\text { Wechsler; language, attention, } \\
\text { memory, visual-spatial } \\
\text { function, motor function, } \\
\text { problem solving }\end{array}$ & $\begin{array}{l}\text { Language } \leftrightarrow \\
\text { Attention } \leftrightarrow \\
\text { Memory, learning } \leftrightarrow \\
\text { Problem solving } \leftrightarrow\end{array}$ & $\begin{array}{l}\text { Visual-spatial skills } \downarrow \\
\text { Motor skills } \downarrow \\
\text { Psychomotor function } \downarrow\end{array}$ \\
\hline Leonberg $(1998)^{58}$ & 9 & Cross-sectional & SBS (67) & $1(11)$ & $4.9 \mathrm{y}$ & $0(0)$ & $15 \mathrm{~m}$ & Reference data & $\begin{array}{l}\text { Language, auditory memory, } \\
\text { visual-motor interaction }\end{array}$ & $\begin{array}{l}\text { Language } \leftrightarrow \\
\text { Auditory memory } \leftrightarrow\end{array}$ & Perceptual motor skills $\leftrightarrow$ \\
\hline O'Connor $(1988)^{57}$ & 12 & Cross-sectional & $\begin{array}{l}\text { SBS (50), } \\
\text { dysmotility (50) }\end{array}$ & $0(0)$ & $5.7 \mathrm{y}$ & $12(100)$ & $52 \mathrm{~m}$ & Reference data & $\begin{array}{l}\text { Wechsler; visual-motor } \\
\text { interaction }\end{array}$ & Intelligence $\leftrightarrow$ & Perceptual motor skills $\downarrow$ \\
\hline
\end{tabular}

improved compared to reference group. *impaired $=$ at least half of patients presenting with scores $<1 \mathrm{SD}$ of the normative mean or significant difference compared to controls ( $<<0.05$ ). 


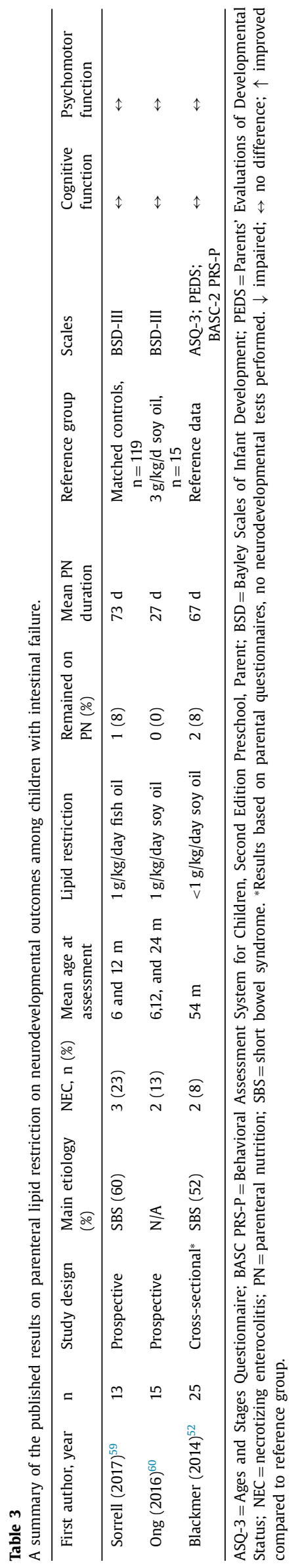

criteria of IF. One study did not report patient baseline diagnoses in detail, ${ }^{62}$ while SBS children comprised the majority in others and remaining patients had been dependent on PN for variable conditions. ${ }^{54,61}$ In the two prospective studies using the Bayley Infant Scales, patient age at the latest follow-up was one or two years, ${ }^{61,62}$ while the parental survey was conducted at mean age of 4.5 years in the cross-sectional study. ${ }^{54}$ In these studies patients receiving reduced fish oil or soy oil-based PN were reported to have similar short-term neurodevelopmental outcomes compared to children receiving standard parenteral lipids. ${ }^{54,61,62}$

\section{Physical quality of life}

Decreased HRQOL due to physical symptoms, physical dysfunction, or child's perceptions about their health ${ }^{25-28,56,63}$ was reported in all studies measuring physical health dimensions of IF children. Specifically, increased stooling frequency, loose stools, and daily abdominal pain were common. ${ }^{25,27,28}$ School-aged IF patients, $80 \%$ of whom were off PN, self-reported stooling frequency was $>3$ times a day in $40 \%$, stools were loose or watery in $60 \%$, and $50 \%$ experienced daily abdominal pain. ${ }^{27}$ Half of the parents of IF toddlers reported their children's HRQOL decreased because of diarrhea. ${ }^{25}$ In a retrospective study recording parent's opinions on their child's bowel function before and after autologous intestinal reconstruction surgery, bowel habits were found to improve postoperatively, however, stooling frequency or consistency were not defined and preoperative bowel function was based on descriptions made after surgery. ${ }^{64}$ One study addressing the influence of an enterostomy found that parents of infants with a stoma reported their children slept better and cried less compared to other infants. On the other hand, adolescents with an enterostomy had more negative thoughts about their health than those without a stoma. ${ }^{63}$

\section{Emotional quality of life}

In the PedsQL questionnaire, emotional QOL scores sum up the self-reported frequency of sleeping problems, worries, and feelings of fear, sadness, and anger. ${ }^{2}$ None of the studies using the PedsQL questionnaire found worse emotional functioning scores among IF children compared to controls, ${ }^{25-27,56}$ although decreased parent proxy scores for emotional functioning were reported in school-aged children weaned off PN. ${ }^{26}$ Similarly, in a Swedish population-based study among children receiving home PN, parents considered their children more anxious, shy, and sensitive as well as more distressed when being alone compared to population norms; in that study, no patient self-reports were collected. ${ }^{55}$ Instead, a French study among children receiving home PN asked specific questions about emotions and reported children aged 3-11 years had negative thoughts about hospitals, health, doctors, medications, obligations, and about being a grown-up, whereas adolescents had more negative thoughts about world events, doctors, medications, and sports when compared to healthy controls. ${ }^{63}$

\section{Social quality of life}

Among IF children both on PN and after weaning off PN, all but one study reported restricted social life based on patient and parent proxy reports. ${ }^{25-28,55,56,63}$ Social restrictions influenced particularly older children: in one study, decreased social HRQOL among toddlers but not infants was reported, ${ }^{25}$ and another study found decreasing psychosocial scores with increasing patient age. ${ }^{26}$ French PN-dependent adolescents had negative emotions about sports while younger patients reported similar social QOL scores than healthy controls. ${ }^{63}$ Unsurprisingly, the presence of a stoma also had a negative influence on adolescents' social life. ${ }^{63}$ The 
high scores for internalizing behavioral problems detected among Swedish children on home PN also suggest decreased social competence. ${ }^{55}$ In interviews, children raised fecal incontinence as well as PN-related restrictions on their physical activity, sleepovers, and travelling as the most important social limitations. ${ }^{28}$

\section{School functioning}

School functioning scores differed across age groups and countries. Most toddlers and school-aged children dependent on $\mathrm{PN}^{25,55,56}$ as well as school-aged children weaned off $\mathrm{PN}^{26,28,56}$ reported restricted kindergarten or school functioning. Over half of Swedish home PN patients received support from external caregivers at school or daycare. ${ }^{55}$ On the other hand, in one study, school-aged children of whom most had weaned off PN reported similar school functioning scores compared to controls although their parents proxy answers scored lower compared to control proxy. $^{27}$ In the French study, adolescents dependent on PN reported even better school functioning than controls. ${ }^{63}$

\section{Neurocognitive outcomes}

In the recent studies evaluating the neurodevelopmental outcomes among IF children aged $<2$ years, the majority of patients were born preterm and had IF due to SBS. ${ }^{5,38}$ Cognitive impairment was observed in $20 \%$, two thirds presented with mental ability scores below $1 \mathrm{SD},{ }^{38}$ and receptive language skills were below 1 SD in half of patients. ${ }^{5}$ Two earlier studies among preschool-aged children did not report prematurity rates but found patients' neurodevelopmental scores within normal limits, ${ }^{59,60}$ however, one third performed poorly on receptive language function. ${ }^{60}$ Instead, no significant differences in any aspects of cognitive function were detected among school-aged SBS children born before the 21st century when compared to cystic fibrosis patients. ${ }^{58}$

Prematurity, low birth weight, high number of surgical procedures, septic episodes, long intensive care unit or hospital stay, and hyperbilirubinemia were found to be negatively associated with IF patients' cognitive outcomes. ${ }^{5,38,59}$ NEC is a well-established independent predictor of neurodevelopmental dysfunction even when the effect of prematurity has been taken into account. ${ }^{31,33,34}$ Accordingly, the only study analyzing the effects of baseline diagnosis on neurodevelopment in pediatric IF identified NEC as a predictor of a poor neurocognitive outcome. ${ }^{5}$

No study found duration of PN associated with cognitive impairment. Among patients having received lipid-restricted PN for less than three months and undergoing cognitive evaluation at the age of one or two years or between $2-5$ years, ${ }^{54,62}$ signs of essential fatty acid deficiency, duration of lipid restriction, or the absolute amount of PN lipids showed no correlation with neurodevelopmental outcomes. Children who were administered fish oilbased PN for median 73 days showed similar neurodevelopmental scores at 6 and 12 months compared to matched controls. ${ }^{61}$

\section{Psychomotor outcomes}

Impaired psychomotor skills were a uniform finding in studies assessing PN-dependent patients (Table 2), and among IF children aged $<2$ years, particularly gross motor skills were frequently delayed. ${ }^{5,38}$ In addition, decreased visual-motor function was observed among toddlers and impaired visual-spatial skills and psychomotor function among school-aged children. ${ }^{58,59}$ Tendency towards delayed psychomotor skills also emerged in parent interviews: $40 \%$ of IF toddlers were reported to have difficulties in achieving normal developmental milestones, ${ }^{25}$ and parents rated the overall developmental progress of children undergoing autologous intestinal reconstruction surgery as "poor". ${ }^{64}$ Only one study including only nine IF patients, who had all weaned off PN, reported normal motor skills at median age of five years. ${ }^{60}$

\section{Caregivers' quality of life}

Caregivers of adult home PN patients frequently report depression, sleep disturbances, social isolation, and economic distress. ${ }^{19,20}$ The severity of these symptoms associates with patient HRQOL and even with their bloodstream infection frequency, ${ }^{19}$ demonstrating the importance of caregiver coping and its influence on the patient health. The few studies specifically addressing the well being of parents of children on home PN report impaired quality of life, ${ }^{63}$ inadequate social support, ${ }^{55}$ and decreased social functioning. ${ }^{25}$ Parents of SBS children reported worse HRQOL and family relationships compared to families of other chronically ill, hospitalized children. ${ }^{56}$ Extending period of time since the latest abdominal surgery or hospitalization as well as lower frequency of abdominal pain were also related with decreased parental stress. ${ }^{27}$ One study comparing SBS children below five years of age to older patients reported parental satisfaction with daily activities and family relationships better in the older age group; on the other hand, satisfaction with healthcare services was worse among parents of children aged over five years. ${ }^{56}$

\section{Conclusions and challenges for future research}

Is summary, the HRQOL of IF children is influenced particularly by physical symptoms such as abdominal pain as well as social limitations, which seem to be more disturbing among the older patients. Negative emotions were detected when specific questions were asked, ${ }^{44}$ whereas more generic PedsQL questions failed to reveal decreased emotional QOL. Although many studies reported worse school functioning among IF compared to healthy children, even patients on home PN were able to attend school and some reported even better school experiences compared to controls. Apparently, measures of social support for school arrangements and other activities of everyday life influencing patient experiences and coping may show great variability between different countries and schools.

The use of generic HRQOL questionnaires may miss the impact of disease-specific symptoms and PN-related challenges on children's HRQOL. Similar to adults, ${ }^{17,18}$ a disease-specific survey designated to pediatric IF population would likely more reliably reveal how satisfied IF children are with their everyday life and specify which health issues have the greatest impact on their overall well-being. Since baseline diagnosis, PN dependence, and the presence of stomas and central lines affect both the prognosis of IF and the subjective well-being of adult patients, ${ }^{10,14,17}$ their impact on HRQOL should be systematically assessed also in the pediatric population. Indeed, in one study, $65 \%$ of parents thought the PedsQL questionnaire failed to address important effects of IF on their children and families. ${ }^{25}$ In addition, the frequently decreased HRQOL of parents likely deserves more attention from medical professionals, as studies among adults demonstrate caregiver exhaustion endangering patients' well being.

Data on the neurodevelopmental outcomes in children with IF is scarce and based on small studies, which are not directly comparable due to varying methodology, treatment eras, and age groups. The recent studies taking into account the effects of prematurity and patient baseline characteristics are also limited by their short follow-up times, since neurodevelopmental tests during infancy predict poorly the cognitive outcomes obtained at school age. ${ }^{51}$ Studies evaluating neurodevelopment in relation to restricted parenteral lipid delivery, on the other hand, have been restricted to children dependent on PN for short time periods and apart from one study using parent-rating instruments, the results are based 
on follow-ups not extending beyond the age of two years. Nevertheless, IF children appear to be at significant risk for delayed psychomotor and cognitive development. Strategies to identify the children at the greatest risk are needed to enable early interventions. Recent studies included higher proportions of NEC and preterm children and found worse cognitive outcomes compared to reports from the 20th century; such results may be partly explained by the improved survival of severely ill and preterm children in the current era. Future studies addressing the neurodevelopmental outcomes of IF children should preferably extend until school age and take into account the multiple confounders influencing the cognitive outcomes, such as prematurity, other comorbidities, and the etiology of IF. Finally, in addition to testing of individual patients, the use of validated parent rating instruments may serve as an option to screen larger patient cohorts and thereby increase our understanding of the long-term consequences of childhood IF on neurodevelopmental outcomes. ${ }^{54}$

\section{Conflicts of interest}

The authors have no conflicts of interest to declare.

\section{References}

1. The World Health Organization Quality of Life assessment (WHOQOL). position paper from the World Health Organization. Soc Sci Med. 1995;41:1403-1409.

2. Varni JW, Burwinkle TM, Seid M, Skarr D. The PedsQL 4.0 as a pediatric population health measure: feasibility, reliability, and validity. Ambul Pediatr. 2003;3:329-341.

3. Varni JW, Limbers CA, Burwinkle TM. Parent proxy-report of their children's health-related quality of life: an analysis of 13,878 parents' reliability and validity across age subgroups using the PedsQL 4.0 Generic Core Scales. Health Qual Life Outcomes. 2007;5:2 https://doi.org/. doi:10.1186/1477-7525-5-2.

4. Rogers EE, Hintz SR. Early neurodevelopmental outcomes of extremely preterm infants. Semin Perinatol. 2016;40:497-509.

5. So S, Patterson C, Gold A, Rogers A, et al. Early neurodevelopmental outcomes of infants with intestinal failure. Early Hum Dev. 2016;101:11-16.

6. Lauriti G, Zani A, Aufieri R, Cananzi M, et al. Incidence, prevention, and treatment of parenteral nutrition-associated cholestasis and intestinal failure-associated liver disease in infants and children: a systematic review. JPEN J Parenter Enter Nutr. 2014:38:70-85.

7. D’Antiga L, Goulet O. Intestinal failure in children: the European view. J Pediatr Gastroenterol Nutr. 2013;56:118-126.

8. Squires RH, Duggan C, Teitelbaum DH, Wales PW, et al. Natural history of pediatric intestinal failure: initial report from the pediatric intestinal failure consortium. J Pediatr. 2012;161:723-728 e2.

9. Fullerton BS, Sparks EA, Hall AM, Duggan C, et al. Enteral autonomy, cirrhosis, and long term transplant-free survival in pediatric intestinal failure patients. $J$ Pediatr Surg. 2016;51:96-100.

10. Petit LM, Girard D, Ganousse-Mazeron S, Talbotec C, et al. Weaning off prognosis factors of home parenteral nutrition for children with primary digestive disease. J Pediatr Gastroenterol Nutr. 2016;62:462-468.

11. Quiros-Tejeira RE, Ament ME, Reyen L, Herzog F, et al. Long-term parenteral nutritional support and intestinal adaptation in children with short bowel syndrome: a 25 year experience. J Pediatr. 2004;145:157-163.

12. Duggan CP, Jaksic T. Pediatric Intestinal Failure. $N$ Engl $J$ Med. 2017;377:666-675.

13. Merras-Salmio L, Mutanen A, Ylinen E, Rintala R, et al. Pediatric intestinal failure-the key outcomes for the first 100 patients treated in a national tertiary referral center during 1984-2017. JPEN J Parenter Enter Nutr. 2018 In press.

14. Pakarinen MP, Koivusalo AI, Rintala RJ. Outcomes of intestinal failure-a comparison between children with short bowel and dysmotile intestine. J Pediatr Surg. 2009;44:2139-2144

15. Kelly DG, Tappenden KA, Winkler MF. Short bowel syndrome: highlights of patient management, quality of life, and survival. JPEN J Parenter Enter Nutr. 2014;38:427-437.

16. Jeppesen PB, Langholz E, Mortensen PB. Quality of life in patients receiving home parenteral nutrition. Gut. 1999;44:844-852.

17. Baxter JP, Fayers PM, McKinlay AW. The clinical and psychometric validation of a questionnaire to assess the quality of life of adult patients treated with long-term parenteral nutrition. JPEN J Parenter Enter Nutr. 2010;34:131-142.

18. Berghofer P, Fragkos KC, Baxter JP, Forbes A, et al. Development and validation of the disease-specific short bowel syndrome-quality of life (SBS-QoL) scale. Clin Nutr. 2013;32:789-796.

19. Smith CE, Piamjariyakul U, Yadrich DM, Ross VM, et al. Complex home care: part III-economic impact on family caregiver quality of life and patients' clinical outcomes. Nurs Econ. 2010;28(393-9):414.

20. Winkler MF, Smith CE. Clinical, social, and economic impacts of home parenteral nutrition dependence in short bowel syndrome. JPEN J Parenter Enter Nutr. 2014;38:32S-37S.
21. Mutanen A, Makitie O, Pakarinen MP. Risk of metabolic bone disease is in creased both during and after weaning off parenteral nutrition in pediatric intestinal failure. Horm Res Paediatr. 2013;79:227-235.

22. Diamanti A, Bizzarri C, Basso MS, Gambarara M, et al. How does long-term parenteral nutrition impact the bone mineral status of children with intestinal failure? J Bone Miner Metab. 2010;28:351-358.

23. Ylinen E, Merras-Salmio L, Gunnar R, Jahnukainen $T$, et al. Intestinal failure as a significant risk factor for renal impairment in children. Nutrition. 2018;45:90-93.

24. Ubesie AC, Kocoshis SA, Mezoff AG, Henderson CJ, et al. Multiple micronutrient deficiencies among patients with intestinal failure during and after transition to enteral nutrition. J Pediatr. 2013;163:1692-1696.

25. Sanchez SE, McAteer JP, Goldin AB, Horslen S, et al. Health-related quality of life in children with intestinal failure. J Pediatr Gastroenterol Nutr. 2013;57: 330-334.

26. Olieman JF, Penning C, Poley MJ, Utens EM, et al. Impact of infantile short bowel syndrome on long-term health-related quality of life: a cross-sectional study. Pediatr Surg. 2012;47:1309-1316.

27. Mutanen A, Kosola S, Merras-Salmio L, Kolho KL, et al. Long-term health-related quality of life of patients with pediatric onset intestinal failure. J Pediatr Surg. 2015;50:1854-1858.

28. Emedo MJ, Godfrey EI, Hill SM. A qualitative study of the quality of life of children receiving intravenous nutrition at home. J Pediatr Gastroenterol Nutr. 2010:50:431-440.

29. Wang X, Xu Z, Miao CH. Current clinical evidence on the effect of general anesthesia on neurodevelopment in children: an updated systematic review with meta-regression. PLoS One. 2014;9:e85760.

30. Flick RP, Katusic SK, Colligan RC, Wilder RT, et al. Cognitive and behavioral outcomes after early exposure to anesthesia and surgery. Pediatrics. 2011;128:e1053-e1061.

31. Shah DK, Doyle LW, Anderson PJ, Bear M, et al. Adverse neurodevelopment in preterm infants with postnatal sepsis or necrotizing enterocolitis is mediated by white matter abnormalities on magnetic resonance imaging at term. $J$ Pediatr. 2008;153(170-5):175 e1.

32. Mziray-Andrew $\mathrm{CH}$, Sentongo TA. Nutritional deficiencies in intestinal failure. Pediatr Clin North Am. 2009;56:1185-1200.

33. Schulzke SM, Deshpande GC, Patole SK. Neurodevelopmental outcomes of very low-birth-weight infants with necrotizing enterocolitis: a systematic review of observational studies. Arch Pediatr Adolesc Med. 2007;161:583-590.

34. Ping LL, Jiang ZD. Comparison of brainstem auditory evoked response at different click rates between preterm babies after neonatal necrotizing enterocolitis and healthy preterm babies. Neonatology. 2014;106:317-322.

35. Minutillo C, Rao SC, Pirie S, McMichael J, et al. Growth and developmental outcomes of infants with gastroschisis at one year of age: a retrospective study. $J$ Pediatr Surg. 2013;48:1688-1696.

36. Festen S, Brevoord JC, Goldhoorn GA, Festen C, et al. Excellent long-term outcome for survivors of apple peel atresia. J Pediatr Surg. 2002;37:61-65.

37. van Manen M HendsonL, Wiley M, Evans M, Taghaddos S, et al. Early childhood outcomes of infants born with gastroschisis. I Pediatr Surg. 2013;48: $1682-1687$.

38. Chesley PM, Sanchez SE, Melzer L, Oron AP, et al. Neurodevelopmental and cognitive outcomes in children with intestinal failure. J Pediatr Gastroenterol Nutr. 2016;63:41-45

39. Belkind-Gerson J, Carreon-Rodriguez A, Contreras-Ochoa CO, Estrada-Mondaca S, et al. Fatty acids and neurodevelopment. J Pediatr Gastroenterol Nutr. 2008;47(Suppl. 1):S7-S9.

40. Gunnar R, Lumia M, Pakarinen MP, Merras-Salmio L. Children undergoing intestinal rehabilitation are at risk for essential fatty acid deficiency. JPEN J Parenter Enter Nutr. 2018 In press.

41. Greenley RN, Josie KL, Drotar D. Self-reported quality of life among inner-city youth with asthma: an empirical examination of the PedsQL 3.0 asthma module. Ann Allergy Asthma Immunol. 2008;100:106-111.

42. Varni JW, Franciosi JP, Shulman RJ, Saeed S, et al. PedsQL gastrointestinal symptoms scales and gastrointestinal worry scales in pediatric patients with inflammatory bowel disease in comparison with healthy controls. Inflamm Bowel Dis 2015;21:1115-1124.

43. Mohammad S, Kaurs E, Aguirre VP, Varni JW, et al. Health-related quality of life in infants with chronic liver disease. J Pediatr Gastroenterol Nutr. 2016;62:751-756

44. Manificat S, Dazord A. Infant, child and adolescent quality of life: surveys performed in a European context. Expert Rev Pharmacoecon Outcomes Res. 2002;2:589-596.

45. Landgraf JL, Abetz L, Ware JE, eds. The CHQ User's Manual. Boston: The Heath Institute, New England Medical Center; 1996.

46. Ivanova MY, Dobrean A, Dopfner M, Erol N, et al. Testing the 8-syndrome structure of the child behavior checklist in 30 societies. J Clin Child Adolesc Psychol 2007;36:405-417.

47. Henderson S, Duncan-Jones P, Byrne DG, Scott R. Measuring social relationships The Interview Schedule for Social Interaction. Psychol Med. 1980;10:723-734.

48. Bayley N. The Psychological Corporation. Bayley scales of infant development. San Antonio, TX; 1993.

49. Mullen EM. Mullen Scales of Early Learning Item Administration Book. Pennsylvania, US: American Guidance Service; 1995

50. Kilbride HW, Aylward GP, Doyle LW, Singer LT et al., Prognostic neurodevelopmental testing of preterm infants: do we need to change the paradigm? J Perinatol 2017;37:475-479. 
51. Hack M, Taylor HG, Drotar D, Schluchter M, et al. Poor predictive validity of the Bayley scales of infant development for cognitive function of extremely low birth weight children at school age. Pediatrics. 2005;116:333-341.

52. Griffiths R. The abilities of young children: a comprehensive system of measurement for the first eight years of life. Association for Research in Infant and Child Development. Bucks, UK, Oxford, UK: The Test Agency; 1984:101-172

53. Wechsler D. Wechsler Intelligence Scale for Children. San Antonio, TX: Psychological Corporation; 1991.

54. Blackmer AB, Warschausky S, Siddiqui S, Welch KB, et al. Preliminary findings of long-term neurodevelopmental outcomes of infants treated with intravenous fat emulsion reduction for the management of parenteral nutrition-associated cholestasis. JPEN J Parenter Enter Nutr. 2015;39:34-46.

55. Engstrom I, Bjornestam B, Finkel Y. Psychological distress associated with home parenteral nutrition in Swedish children, adolescents, and their parents: preliminary results. J Pediatr Gastroenterol Nutr. 2003;37:246-250.

56. Pederiva F, Khalil B, Morabito A, Wood SJ. Impact of short bowel syndrome on quality of life and family: the patient's perspective. Eur J Pediatr Surg. 2018 In press.

57. Schwankovsky L, Mousa H, Rowhani A, DI Lorenzo C, et al. Quality of life outcomes in congenital chronic intestinal pseudo-obstruction. Dig Dis Sci. 2002;47:1965-1968.
58. Beers SR, Yaworski JA, Stilley C, Ewing L, et al. Cognitive deficits in school-age children with severe short bowel syndrome. J Pediatr Surg. 2000;35:860-865.

59. O'Connor MJ, Ralston CW, Ament ME. Intellectual and perceptual-motor performance of children receiving prolonged home total parenteral nutrition. Pediatrics. 1988;81:231-236.

60. Leonberg BL, Chuang E, Eicher P, Tershakovec AM, et al. Long-term growth and development in children after home parental nutrition. J Pediatr. 1998;132:461-466.

61. Sorrell M, Moreira A, Green K, Jacob R, et al. Favorable outcomes of preterm infants with parenteral nutrition-associated liver disease treated with intravenous fish oil-based lipid emulsion. J Pediatr Gastroenterol Nutr. 2017;64:783-788.

62. Ong ML, Purdy IB, Levit OL, Robinson DT, et al. Two-year neurodevelopment and growth outcomes for preterm neonates who received low-dose intravenous soybean oil. JPEN J Parenter Enter Nutr. 2016. doi:10.1177/0148607116674482.

63. Gottrand F, Staszewski P, Colomb V, Loras-Duclaux I, et al. Satisfaction in different life domains in children receiving home parenteral nutrition and their families. J Pediatr. 2005;146:793-797.

64. Edge H, Hurrell R, Bianchi A, Carlson G, et al. Caregiver evaluation and satisfaction with autologous bowel reconstruction in children with short bowel syndrome. J Pediatr Gastroenterol Nutr. 2012;54:510-515. 